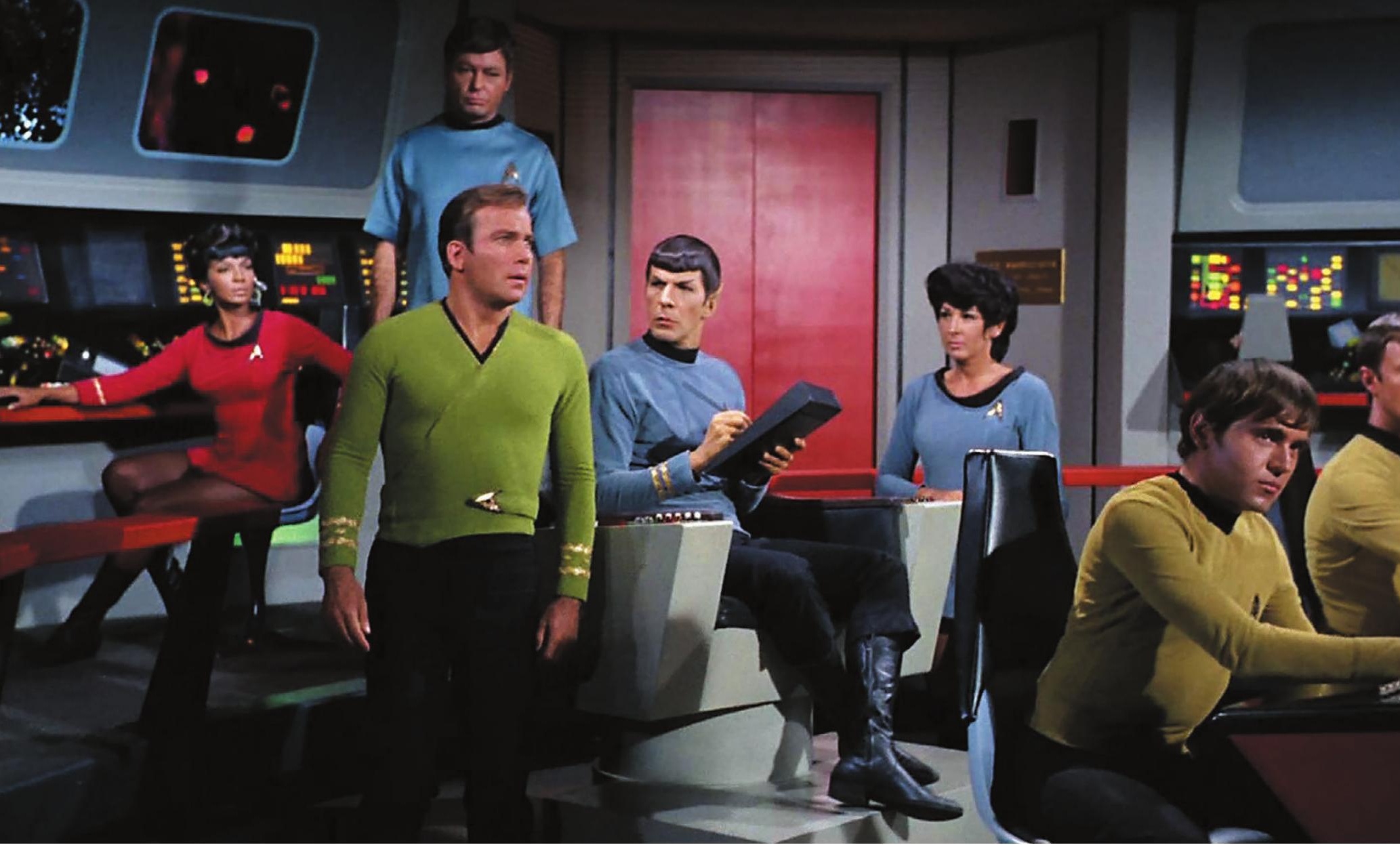

The original crew of the USS Enterprise.

SCIENCE FICTION

Boldly going for 50 years

Sidney Perkowitz scans the impacts of Star Trek on science, technology and society.

$\mathrm{H}$ alf a century ago, in September 1966, the first episode of Star Trek aired on the US television network NBC. NASA was still three years short of landing people on the Moon, yet the innovative series was soon zipping viewers light years beyond the Solar System every week. After a few hiccups it gained cult status, along with the inimitable crew of the starship USS Enterprise, led by Captain James T. Kirk (William Shatner). It went into syndication and spawned 6 television series up to 2005; there are now also 13 feature films, with Star Trek Beyond debuting in July this year.

Part of Star Trek's enduring magic is its winning mix of twenty-third-century technology and the recognizable diversity and complexity enshrined in the beings - human and otherwise - created by the show's originator Gene Roddenberry and his writers. As Roddenberry put it, "We stress humanity." The series wore its ethics on its sleeve at a time when the Vietnam War was raging and anti-war protests were proliferating, along with racial tensions that culminated in major US urban riots in 1967-68. Roddenberry's United Federation of Planets, a kind of galactic United Nations, is an advanced society wielding advanced technology, and the non-militaristic aims of the Enterprise are intoned at the beginning of every episode in the original series (TOS): "To explore strange new worlds; to seek out new life and new civilizations; to boldly go where no man [later, 'no one'] has gone before."

Over the decades, Star Trek technologies have fired the imaginations of physicists, engineers and roboticists. Perhaps the most intriguing innovation is the warp drive, the propulsion system that surrounds the Enterprise with a bubble of distorted spacetime and moves the craft faster than light to traverse light years in days or weeks. In 1994, theoretical physicist Miguel Alcubierre showed that such a bubble is possible within Albert Einstein's general theory of relativity, but would demand massive amounts of negative energy, also known as exotic matter (M. Alcubierre Class. Quantum Grav. 11,

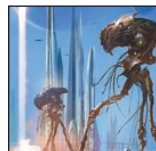

SCIENCE FICTION

A Nature special issue

nature.com/scifispecial
L73; 1994). This is not known to exist except (possibly) in minuscule quantities; and some physicists speculate that the Alcubierre drive might annihilate the destined star system. The warp drive remains imaginary - for now.

However, another application of warped space-time in the series has been realized: a cloaking device that shields spacecraft from view by bending light around them. In 2006, electrical engineers David Smith and David Schurig built a 'metamaterial' electromagnetic cloak that hid an object from microwaves by refracting them to pass around it, much as water flows around an obstacle (D. Schurig et al. Science 314, 977-980; 2006). Now, similar diversionary tactics are being used to hide small objects under visible light, for instance by electrical engineer Xingjie Ni and his colleagues, who devised a "skin cloak" 80 nanometres thick to do the job (X. Ni et al. Science 349, 1310-1314; 2015).

The exotic Enterprise transporter, which instantaneously dematerializes and teleports people and things (inspiring the catchphrase "Beam me up"), was supposedly conceived to save the costs of staging repeated spaceship landings. It has a real analogue in quantum 

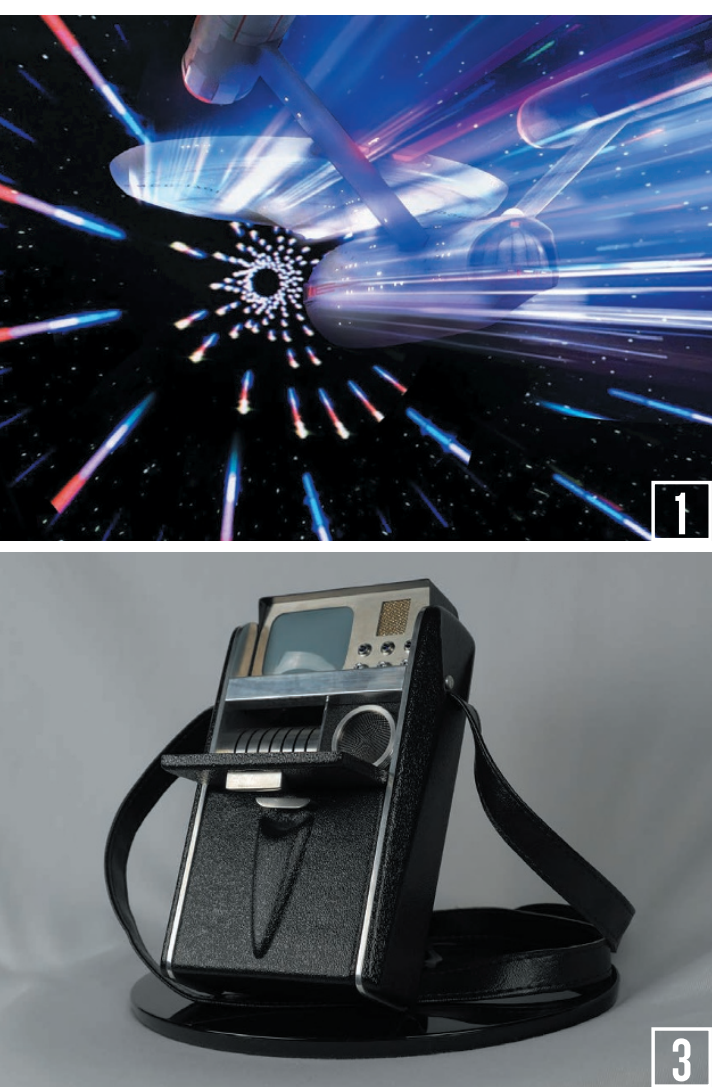

teleportation. In 2015, for instance, quantum optics researcher Hiroki Takesue and his colleagues harnessed entanglement to send the properties of one photon to another over 100 kilometres of optical fibre (H. Takesue et al. Optica 2, 832-835; 2015). Above the atomic level, however, we're a long way from teleporting entire organisms or objects.

Other Star Trek technologies anticipated modern trends. The tricorder that TOS medic Leonard 'Bones' McCoy (DeForest Kelley) uses for diagnosis has spawned real devices, such as SCOUT from medical-technology company Scanadu in Moffett Field, California. Meanwhile, activity trackers already perform basic health monitoring, recording pulse rate, calorie intake and quality of sleep.

Artificial intelligence has begun to emerge in technologies such as speech recognition by Apple's personal-assistant program Siri, Google's self-driving car and the 'all-terrain' Atlas robot created for the US Defense Advanced Research Projects Agency. All are significant developments that could pave the way to an eventual approximation of Lieutenant Commander Data (Brent Spiner), the sentient android who debuted on television series The Next Generation in the late 1980s.

Star Trek's holodeck - the immersive virtual-reality environment in which the Enterprise crew visits simulated locales is also years away, but huge advances in the technology are afoot. The Oculus Rift headset, for instance, provides a visual and auditory virtual-reality experience, but must be
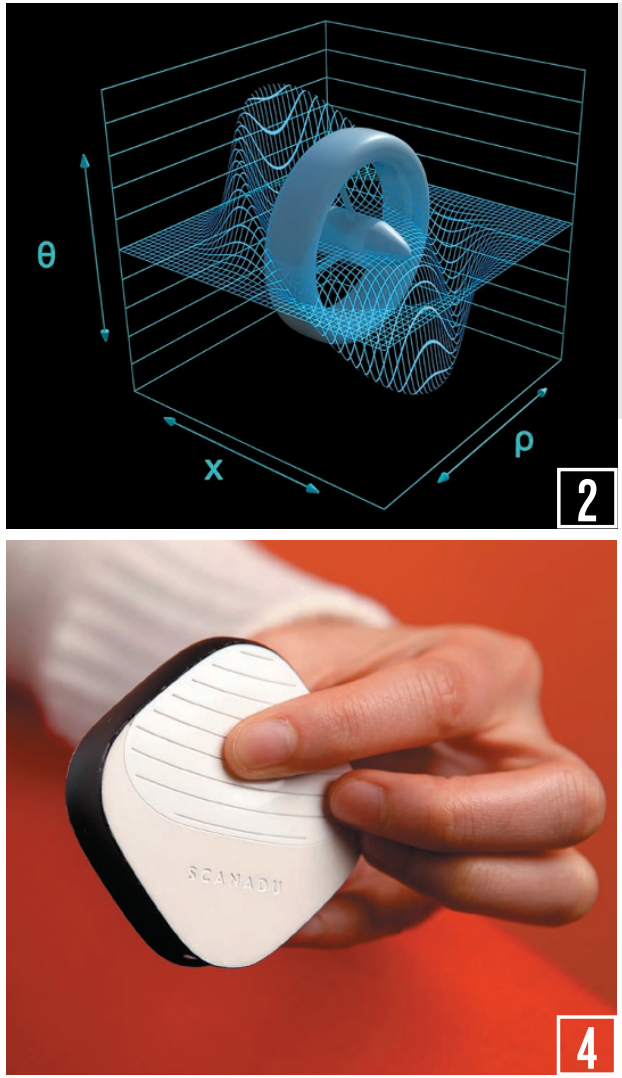

tethered to a computer, thus falling short of delivering the seamless holodeck experience.

Three-dimensional printers, which lay down successive layers of material to form intricate shapes, are now being adapted to handle food, perhaps a step towards Enterprise meal replicators. The Creative Machines Lab, then at Cornell University in Ithaca, New York, designed one model as part of its open-

\section{access Fab@Home}

"Many young would-be scientists have found the series project, and Natural Machines in Barcelona, Spain, touts its Foodini printer as simplifying the making of inspirational." textured or layered foods such as ravioli.

More generally, and arguably with greater long-term significance, Star Trek raised enthusiasm for space exploration and science. In 1975, fans convinced NASA to name its first test space shuttle orbiter Enterprise (the craft was unpowered and never reached space). And many young would-be scientists have found the series inspirational.

Its social message has been no less important. The federation ethic ensured that Kirk, Next Generation Captain Jean-Luc Picard (Patrick Stewart) and their successors 'waged peace' even when confronted by aliens such as the Klingons, a people genetically predisposed to hostility. The February 1968 episode 'A Private Little War', an allegory about Vietnam, was a pointed example. Roddenberry believed that humanity must learn

\section{TREK TECHNOLOGIES}

The series' futuristic technologies have inspired real-life innovations - some further advanced than others. A version of the warp drive that propelled the USS Enterprise faster than light (1) was proposed by physicist Miguel Alcubierre in 1994 (2), but remains conceptual. The diagnostic tricorder ( 3 ) has been realized in Scanadu's SCOUT (4) and app, which measure vital signs such as blood pressure.

to delight in difference, even in alien lifeforms, and ready itself to "meet the diversity that is almost certainly out there".

Star Trek's portrayal of human diversity and refusal to engage in national exceptionalism remain landmark achievements. Emerging at a time of racial exclusion in US television, TOS crew included Lieutenant Nyota Uhura (Nichelle Nichols), the first prominent African American female role in a US television series, as well as the 'pan-Asian' helmsman Hikaru Sulu (George Takei), Russian navigator Pavel Chekov (Walter Koenig) — and, of course, Leonard Nimoy's star turn as halfVulcan Commander Spock. Native American first officer Chakotay (Robert Beltran) emerged in the series Voyager (1995-2001). The gender balance tended to the heavily male until the advent of Voyager Captain Kathryn Janeway (Kate Mulgrew), with halfKlingon chief engineer B'Elanna Torres (Hispanic actress Roxann Dawson). Real-world impacts abound. Nichols, for instance, has related how US civil-rights leader Martin Luther King urged her to remain in the series when she was considering other professional options. Her character, in turn, inspired astronaut Mae Jemison, the first African American woman to be sent into space by NASA.

Fifty years later, how does our world compare with Roddenberry's universe? The changes in technology are transformational; and although interstellar travel has yet to become reality, NASA's projected 2030s human mission to Mars follows the dream "to boldly go". The progressive social values that Star Trek pioneered on television are now much more widely held. But new conflicts and geopolitical stand-offs have erupted, despite efforts by our own federation, the United Nations. Amid these shifts and tensions, this vastly influential franchise continues to carry a subtle but clear message - we can be better than we are.

Sidney Perkowitz (http://sidneyperkowitz. net) is Charles Howard Candler Emeritus Professor of Physics at Emory University in Atlanta, Georgia. He writes frequently about science, technology and culture; his latest books are Universal Foam 2.0 and Frankenstein 2018 (in progress).

e-mail:physp@emory.edu 